\title{
Triple-negative breast cancer: the reality in Chile and in Latin America
}

\author{
Christian Caglevic ${ }^{1}$, Jaime Anabalón ${ }^{2}$, Cristian Soza ${ }^{3,4}$, Elizabeth Milla ${ }^{2}$, Fancy Gaete ${ }^{5}$, Ana María Carrasco ${ }^{6}$, Sergio Panay ${ }^{2}$, \\ Carlos Gallardo ${ }^{6}$, Mauricio Mahave ${ }^{6}$
}

\author{
${ }^{1}$ Medical Oncology Department, Clinica Alemana Santiago; Faculty of Medicine, Universidad del Desarrollo, Santiago 456, Chile \\ ${ }^{2}$ Oncology Institute Arturo López Pérez Foundation, Santiago 878, Chile \\ ${ }^{3}$ School of Biochemistry, Faculty of Science, San Sebastián University, Santiago 1457, Chile \\ ${ }^{4}$ Oncoloop Foundation, Faculty of Medicine, Andrés Bello University, Santiago 890, Chile \\ ${ }^{5}$ Hospital Santiago Oriente Dr Luis Tisné, Santiago 5150, Chile \\ ${ }^{6}$ Oncology Institute Arturo López Pérez Foundation, Santiago 878, Chile
}

Correspondence to: Christian Caglevic. Email: ccaglevic@alemana.cl and oncodemia@yahoo.com

\begin{abstract}
Breast cancer is the leading cause of cancer death among women worldwide. While triple-negative breast cancer is less common among various sub-types of breast cancer, it tends to affect younger women and is more aggressive, having a higher rate of early recurrence and mortality compared to other sub-types. We know about the association between triple-negative breast cancer and BRCA mutations, which are highly prevalent in founding populations of European origin, but the true prevalence of these mutations in Latin American populations is unknown. There is also very little information about the demographic and epidemiological aspects of triple-negative breast cancer in Latin America, which we will try to summarise in this article. In addition, we will try to provide a brief introduction to the most common recommendations for treating this histological class in Latin America.
\end{abstract}

Keywords: breast cancer, triple-negative breast cancer

Published: 22/01/2019

Received: 06/05/2018

ecancer 2019, 13:893 https://doi.org/10.3332/ecancer.2019.893

Copyright: (c) the authors; licensee ecancermedicalscience. This is an Open Access article distributed under the terms of the Creative Commons Attribution License (http://creativecommons.org/licenses/by/3.0), which permits unrestricted use, distribution, and reproduction in any medium, provided the original work is properly cited. 


\section{The epidemiology of breast cancer around the world and in Latin America}

In women, breast cancer is the most common neoplasm and the second cause of death from cancer worldwide [1]. This pathology may present itself in various ways [2] and be related to multiple factors [3]. It is estimated that in 2012, 1.67 million new cases were diagnosed worldwide, corresponding to $25 \%$ of the total number of cancer cases [4]. Demographically speaking, both incidence and mortality rates vary according to the region, ethnic group and socioeconomic level analysed [1, 5, 6]. According to GLOBACAN 2012 estimates, in North America, the age-adjusted breast cancer incidence rate is 91.6 cases per 100,000 women and the age-standardised mortality rate is 14.8 cases per 100,000 women [4]. In the United States, despite the fact that breast cancer is still responsible for more than 40,000 deaths per year, the mortality rate has been decreasing continuously over the last 25 years [7]. In this way, it is estimated that for the decade of $2020-$ 2030 , breast cancer will continue to be the most common cancer, along with lung and prostate cancer, but its mortality rate will drop to lower than that of pancreas and liver cancers [8]. European countries follow a similar trend to that of the United States. The leading neoplasia in women in this region is also breast cancer, affecting more than one in 10 women, and accounting for $28.8 \%$ of all female cancers [9, 10].

Breast cancer has a high incidence rate in Latin America and is on the rise, so it is expected to double over the next decades [11, 12]. In fact, the incidence of this disease in Latin America and the Caribbean is 152,059 new cases (incidence of 42.7/100,000 adjusted by age), producing an age-adjusted mortality rate of 13 per 100,000 women [4]. The situation is made worse by the disparity in access to health services, diagnosis and detection, especially among ethnic minority communities and the lack of a good national cancer population registry in various countries [13]. In general, countries such as Mexico, Panama, Ecuador and Colombia have lower incidence rates than Central and Eastern Europe, similar to those of Asia. On the other hand, countries in the south of Latin America (Uruguay, Argentina and Chile) report higher incidence rates, similar to those of the United States and Europe [11], possibly due to greater access to healthcare and greater technological development, together with fewer people living outside the cities when compared to other countries in the region.

Incidence and mortality rates for this cancer have steadily increased over the last 25 years [14]. In Chile, for example, the increase in the crude incidence rate has, on average, been around $10.7 \%$ of the compound annual growth rate. This means an increase of 28.9 per 100,000 women in 2000 to 39.2 per 100,000 women in 2003 [15]. Similarly, in Brazil, the crude incidence rate has also increased from 22.9 per 100,000 women in 1988 to 68.2 per 100,000 women in 2003 [16].

The mortality rate in Latin American is variable, having decreased in some countries. For example, in Chile, the adjusted mortality rate increased from 1960 to the mid-1980s, but then between 1990 and 2010, there was a turning point, with a slight decrease [17, 18]. Demographic changes, ageing of the population and an increase in the incidence of this disease are factors that most impact the mortality rate in Latin America and the Caribbean. For example, it is estimated that, by 2030 , the number of women over 60 will double and the World Health Organization estimates that by the same date, the number of deaths from breast cancer will increase from 43,208 to 73,542 cases in the region [19].

In Chile, detection and diagnosis programmes together with timely access to treatments have managed to reduce mortality rates despite socio-economic disparities and changes in lifestyles within the population. However, the lack of national cancer population registries makes it difficult to estimate accurately the mortality rate caused by breast cancer [15]. There are only three cancer population registries in Chile: two are located in the south of the country, in the Los Ríos Region and Bío-Bío Province, while the third is located in the Antofagasta Region in the north of Chile. Although numerically speaking, these records represent a low percentage of the population; they show how incidence and mortality rates in a country like Chile vary according to geography and various environmental contexts. For example, in the Antofagasta Region, the type of cancer with the highest incidence in women is non-melanoma skin cancer with a rate of 41.6 per 100,000 women, followed by breast cancer with a rate of 35.9 per 100,000 women. On the other hand, in the Los Ríos Region and Bío-Bío Province, breast cancer is the highest-occurring pathology with incidence rates of 40.7 and 35.3 per 100,000 women, respectively [17]. Breast cancer is not the leading cause of death in either of these regions. Instead, it is lung cancer (Antofagasta) and cancer of the gallbladder and bile ducts (Los Ríos Region and Bío-Bío Province) [20]. This shows the importance and usefulness of implementing national cancer registries in Latin American countries in order to establish strategies for detection and early diagnosis, in planning for access to appropriate treatments and prevention according to the major risk factors present. There is currently a huge effort being made in Chile to improve cancer registries, by seeking realistic ways to increase population sampling in order to have better statistics that may be useful for a better diagnosis and definition of public policies aimed at early diagnosis and timely treatment of cancer. 
ecancer 2019, 13:893

\section{Triple-negative breast cancer: molecular and demographic aspects, impact in Chile and Latin America}

Following the original work of Perou, which showed the existence of intrinsic sub-types of breast cancer defined based on profiles of gene expression [21], a consensus classification based on immunohistochemical markers was established. Each of these groups has its own clinical behaviour with particular patterns of response to specific therapies in some cases.

In relation to the expression of oestrogen receptors, progesterone receptors and HER2 overexpression, four categories have been identified: Luminal A, Luminal B, HER2-amplified and Triple Negative, the latter of which includes tumours that do not express any of other three markers [22].

This group is heterogeneous, containing histological sub-types with especially good prognosis such as adenoid cystic carcinoma and varieties of greater aggressiveness such as metaplastic carcinoma. The basal-like sub-type defined by PAM50 is the most represented in the triple-negative category, where more than $90 \%$ of basal-likes are triple negative, and at the same time, basal-like is the most common sub-type within the triple negatives [23, 24]. Additionally, triple negatives have been subdivided into four more groups on the basis of gene expression, however, up to now, this sub-classification has had no real use in clinical practice [25].

According to various publications worldwide, between $15 \%$ and $20 \%$ of invasive breast tumours belong to the triple-negative group [26-28], with a higher occurrence among women under 40 years of age. The North American literature shows a higher incidence rate among patients of African descent, with a reported prevalence of up to $39 \%$, followed by women of Hispanic origin. Population studies based on registries such as the California Cancer Registry and The Surveillance, Epidemiology, and End Results (SEER) Program of the National Cancer Institute $(\mathrm{NCl})$ report a triple-negative disease prevalence of $12.5 \%$ that is strongly associated with patients under 40 years of age and of African descendent, in addition to low socio-economic levels and people with less access to healthcare [29-32].

In Latin America, breast cancer is the leading cause of death from tumours in young women. Triple-negative breast cancer is becoming a more common situation in young women, accounting for $20 \%$ of deaths due to breast cancer in the 45 years or younger age group, twice as much as the reported rate in developed countries. The reported prevalence of triple-negative disease in Latin America in young women ranges between $18 \%$ and $35 \%$, with the highest rates being reported in countries such as Mexico and Peru [33].

Not much data on triple-negative disease has been published in Chile. A retrospective study in a university centre explored the situation of breast cancer at extreme ages (under 41 years of age and over 69) over a period of 16 years. 12\% of patients in the registry were under 41 years of age, with Luminal B being the most frequent sub-type (43\%), followed by Luminal $A(33.2 \%)$ and triple-negative disease in third place (17.8\%) [34]. Not yet published information from the Oncology Institute, Arturo López Pérez Foundation in Santiago, Chile reports that in 20 new cases of triple-negative breast cancer diagnosed during 2017, only $20 \%$ of patients were under the age of 40 and the average age of all patients was 49 years old, which shows an epidemiological discrepancy compared with known data from other populations of the same regional area. On the other hand, official data from the Luis Tisné Hospital in Santiago, Chile (flagship hospital for the diagnosis and treatment of breast cancer) reviewed for this work, showed that out of a total of 285 biopsies performed on patients with breast cancer between June 2014 and May 2015, only 8.7\% corresponded to the triple-negative sub-type, thus showing a much lower prevalence of this sub-type of breast cancer in a representative sample of Chilean women with breast cancer when compared with other groups in Latin America.

Unfortunately, there is a regional lack in our continent in terms of having real epidemiological knowledge of many oncological pathologies, and in particular, the epidemiology of triple-negative breast cancer. Neither is there any certainty of the magnitude of the problem nor of the differences among countries and among regions within the same country, considering that most of the published data about breast cancer involve the total number of patients independent of the histological sub-types. In the understanding of the most aggressive natural history of triple-negative breast cancer, it is necessary to consider the report of this sub-type of breast cancer within the various health systems of Latin America, given that it may have potential implications in projecting health policies aimed at attacking this disease more quickly and more aggressively in consideration of its high mortality rate and poor prognosis. 


\section{Clinical presentation and natural history}

Compared with Luminal A and Luminal B type tumours, the triple-negative sub-type or variety tends to occur with a larger size, a higher histologic degree and a faster growth. In fact, they can often be investigated as 'interval tumours' during screening programmes. In relation to a possible greater lymph-node involvement, there is no clearly demonstrated association so far. Its frequent metastatic presentation is characterised by a greater visceral involvement, particularly in the central nervous system and lungs, and a lower frequency of bone involvement [35].

These tumours are generally associated with a worse prognosis in relation to luminal tumours, with a less than $80 \%$ chance of surviving 5 years, on average, compared with non-triple-negative tumours, where the chance of surviving 5 years exceeds $90 \%$, according to U.S. data. There are limitations in the understanding of the underlying biology, as well as the lack of specific therapeutic agents for its treatment. Its recurrences are early and systemic, with a significantly higher risk of death during the first 5 years following diagnosis. Up to $50 \%$ of patients diagnosed with non-metastatic triple-negative breast cancer will become ill again and $37 \%$ will die from the disease during the first 5 years after surgery [36, 37]. What was shown is that it has the highest recurrence-free survival rate in patients who underwent neoadjuvant chemotherapy and who managed a pathologic complete response compared to women who did not achieve this goal (HR 0.24 $(95 \% \mathrm{Cl} 0.18-0.33)$ ) [38]. The use of platinum in combination with anthracyclines and taxanes demonstrated a statistically better pathologic complete response (53\%) compared with patients who did not use carboplatin (39\%) with triple-negative breast cancer stages II and III [39], behaviour that in the end may result in a greater hope for recurrence-free survival and, indirectly, the overall survival of these patients. The benefit of using carboplatin-based treatments shows even better results in a pathologic complete response in those groups of patients who are carriers of BRCA mutations [40]. In the presence of metastasis, the median survival is between 9 and 12 months, compared to $2-4$ years observed in other sub-types of breast cancer. [41]

Patients with metastatic disease have a short progression-free survival expectancy following the failure of the first-line chemotherapy with an average of no longer than 4 months, indicating the great need to develop drugs to treat triple-negative breast cancer. With the exception of Olaparib for the treatment of tumours with BRCA germline mutations [42], there are currently no other approved therapies for this group, leaving cytotoxic chemotherapy as a pillar of systemic treatment. On the other hand, the actual prevalence of BRCA mutations is not well known among the various towns and regions of Latin America. There are varying results in different populations within the same country and in populations selected by genetic risk criteria [43, 44].

Various recommendation guidelines for Latin American regarding the management of early and metastatic breast cancer recognise triple-negative breast cancer as a high-risk variety, however, they do not suggest the use of different therapies from those already commonly used for other sub-types (excluding targeted therapies for Luminal HER2), such as treatments based on anthracyclines and taxanes. Triple-negative breast cancer has higher response rates to neoadjuvant chemotherapy in comparison with other sub-types of breast cancer and is known as the triple-negative breast cancer paradox [45]. Advantages of neoadjuvancy include minimising the size of the tumour to allow breast-conserving surgery in selected cases, reducing options for extensive axillary dissection, making an inoperable tumour resectable and allowing an in vivo evaluation of the sensitivity of the tumour to chemotherapy, thereby decreasing the possibilities of metastasis. There is a shortage of public policies and management guidelines on early disease that include studies on BRCA mutations and the use of platinum duplicates in neoadjuvant therapies. In a meta-analysis involving 11,955 patients undergoing neoadjuvant chemotherapy for breast cancer, the pathologic complete response showed a significant correlation with disease-free survival and overall survival [38]. Patients who achieved a pathologic complete response had significantly better results. Recurrencefree survival with an HR of 0.24 and overall survival with an HR of 0.16 indicate that pathologic complete response has a prognostic value in triple-negative breast cancer. The most used adjuvant systemic treatment in Latin America, where neoadjuvancy was not used previously, includes the sequential combination of chemotherapy based on anthracyclines followed by taxanes. Similar confrontation occurs in metastatic disease where, since hormonal therapies cannot be used, the range of options is limited today to systemic therapies which include anthracyclines, taxanes, platinum-based duplicates (e.g. a combination of carboplatin and gemcitabine) and capecitabine, ixabepilone, among other options. 
Table 1. Clinical studies in development for patients with triple-negative breast cancer.

\begin{tabular}{|c|c|c|c|}
\hline Category & Details of the Study & Phase & NCT \\
\hline \multirow[t]{2}{*}{ Inhibitors checkpoint } & $\begin{array}{l}\text { Nab-paclitaxel } \pm \text { atezolizumab (MPDL3280A) in previously untreated } \\
\text { patients (IMpassion130) }\end{array}$ & III & NCT02425891 \\
\hline & $\begin{array}{l}\text { Study of Pembrolizumab (MK-3475) plus chemotherapy versus che- } \\
\text { motherapy plus placebo for inoperable, locally recurring or previously } \\
\text { untreated metastatic triple-negative breast cancer (MK-3475-355 / } \\
\text { KEYNOTE-355) }\end{array}$ & III & NCT02819518 \\
\hline PARP inhibitors & $\begin{array}{l}\text { A Phase 3, open-label, randomized parallel, } 2 \text {-arm, multi-centre study Of } \\
\text { Talazoparib (Bmn 673) versus physician's choice in germline BRCA muta- } \\
\text { tion subjects with locally advanced and/or metastatic breast cancer, who } \\
\text { have received prior chemotherapy regimens for metastatic disease }\end{array}$ & III & NCT01945775 \\
\hline Antiandrogen therapy & $\begin{array}{l}\text { Bicalutamide versus first-line chemotherapy in androgen receptor positive } \\
\text { triple-negative metastatic breast cancer }\end{array}$ & III & NCT03055312 \\
\hline \multirow[t]{2}{*}{ PI3K-AKT-mTOR inhibitors } & Paclitaxel + AZD5363 in first line metastatic (PAKT) & II & NCT02423603 \\
\hline & BYL719 monotherapy in metastatic breast cancer (second line) & II & NCT02506556 \\
\hline Conjugated antibodies & $\begin{array}{l}\text { Randomised, sacituzumab govitecan (IMMU-132) versus treatment of the } \\
\text { doctor's choice in patients with triple-negative metastatic breast cancer } \\
\text { who have received at least two lines of previous treatments }\end{array}$ & III & NCT02574455 \\
\hline
\end{tabular}

In addition to available treatments, considering the poor prognosis of triple-negative breast cancer and the strong aggressiveness of metastatic disease added to the ignorance of the real incidence and prevalence of triple-negative disease in our populations, as well as the urgent need for new treatment options, it makes sense to involve patients in clinical studies [46] and give patients the option of receiving new therapeutic options that can potentially affect a better prognosis and survival rate (Table 1).

\section{Conclusions}

Breast cancer is the leading cause of death in women around the world. Among the sub-types classified by Perou, triple-negative breast cancer has biological characteristics that make it a sub-type with a more aggressive presentation at earlier ages, a very high risk of mortality and/or a quick recurrence rate and, at the same time, high and early failure of systemic therapy in metastatic disease.

In Israel and Europe, triple-negative breast cancer, like ovarian cancer, has been widely associated with populations having a high prevalence of BRCA gene mutations (BRCA 1 and BRCA 2); a situation occurring in various populations worldwide in women who are carriers of these mutations. In Latin America where the known presence of BRCA mutations is much lower than in the other regions mentioned, the prevalence of triple-negative breast cancer ranges between $8 \%$ and $35 \%$ according to different reports. However, the prevalence of this problem is not known for certain because little data has been reported on the various sub-types in the country, and we are limited to information published in reports on regional experiences and series, including information presented at scientific events but not published.

This disinformation must be improved in order to consider health policies that focus on the triple-negative disease; a sub-type of breast cancer with its own characteristics such as its aggressiveness, its occurrence mainly in young women, its high rate of metastasis and mortality when compared with other histological sub-types, all of which convert this sub-type into a unique variety with a worse prognosis.

In locoregional disease, neoadjuvant chemotherapy associated with a pathologic complete response has been shown to have an impact on the survival of these patients. For this reason, this method, often discarded in Latin America for practical reasons such as a lack of rapid access to cancer centres, a lack of knowledge about the natural history of triple-negative breast cancer and the lack of 
multidisciplinary cancer management in some areas, should standardise the use of neoadjuvant chemotherapy in all women in Latin America with triple-negative non-metastatic breast cancer, ideally with combinations containing carboplatin or cisplatin. Unfortunately, to date, the prognosis of the metastatic disease is poor and the option of managing the disease is limited to various palliative chemotherapy options. However, the possibility of including these patients in clinical studies, even women with the locoregional disease, would be highly recommended.

\section{Conflicts of interest}

This publication has not been funded by any industry or by any institution. None of the authors have received payment of any kind for this publication. Christian Caglevic declares the following conflicts of interest:

- Speaker: MSD, GSK, Bayer, BMS, Boehringer Ingelheim, Tecnofarma, Roche

- Principal Investigator: MSD, GSK, Bayer, Boehringer Ingelheim, Astellas, Roche, Astra Zeneca, BMS, Novartis

- Advisory and Consulting: MSD, BMS, Bayer, Astra Zeneca, Boehringer Ingelheim, Lilly, Tecnofarma

- Sponsored Educational Programme: Boehringer Ingelheim, Tecnofarma, BMS, MSD

\section{References}

1. Hiatt RA and Brody JG (2018) Environmental determinants of breast cancer Annu Rev Public Health 39 113-133 https://doi. org/10.1146/annurev-publhealth-040617-014101 PMID: 29328875

2. Kohler BA, Sherman RL, and Howlader N, et al (2015) Annual report to the nation on the status of cancer, 1975-2011, featuring incidence of breast cancer subtypes by race/ethnicity, poverty, and state $J$ Natl Cancer Inst 107(6) djv048 https://doi.org/10.1093/ inci/djv048 PMID: 25825511 PMCID: $\underline{4603551}$

3. Hiatt RA, Porco TC, and Liu F, et al (2014) A multilevel model of postmenopausal breast cancer incidence Cancer Epidemiol Biomarkers Prev 23(10) 2078-2092 https://doi.org/10.1158/1055-9965.EPI-14-0403 PMID: 25017248

4. Ferlay J, Soerjomataram I, and Ervik M, et al (2012) GLOBOCAN 2012 v1.0, Cancer incidence and mortality worldwide: IARC cancerbase No. 11 [Lyon, France: International Agency for Research on Cancer; 2013] [http://globocan.iarc.fr/Pages/fact_sheets_cancer. aspx] Data accessed: 6/4/2018

5. Smith BD, Smith GL, and Hurria A, et al (2009) Future of cancer incidence in the United States: burdens upon an aging, changing nation J Clin Oncol 27(17) 2758-2765 https://doi.org/10.1200/JCO.2008.20.8983 PMID: 19403886

6. DeSantis CE, Ma J, and Goding Sauer A, et al (2017) Breast cancer statistics, 2017, racial disparity in mortality by state $C A$ Cancer J Clin 67(6) 439-448 https://doi.org/10.3322/caac.21412 PMID: 28972651

7. Howlader N, Noone, AM, and Krapcho M, et al (2016) SEER Cancer statistics review, 1975-2013 [National Cancer Institute. Bethesda, MD]. [https://seer.cancer.gov/csr/1975 2013/]

8. Rahib L, Smith BD, and Aizenberg R, et al (2014) Projecting cancer incidence and deaths to 2030: the unexpected burden of thyroid, liver, and pancreas cancers in the United States Cancer Res 74(11) 2913-2921 https://doi.org/10.1158/0008-5472.CAN14-0155 PMID: 24840647

9. Lundqvist A, Andersson E, and Ahlberg I, et al (2016) Socioeconomic inequalities in breast cancer incidence and mortality in Europe-a systematic review and meta-analysis Eur J Public Health 26(5) 804-813 https://doi.org/10.1093/eurpub/ckw070 PMID: $\underline{27221607}$ PMCID: $\underline{5054273}$

10. Ferlay J, Steliarova-Foucher E, and Lortet-Tieulent J, et al (2013) Cancer incidence and mortality patterns in Europe: estimates for 40 countries in 2012 Eur J Cancer 49(6) 1374-1403 https://doi.org/10.1016/i.ejca.2012.12.027 PMID: 23485231

11. Justo N, Wilking N, and Jönsson B, et al (2013) A review of breast cancer care and outcomes in Latin America Oncologist 18(3) 248-256 https://doi.org/10.1634/theoncologist.2012-0373 PMID: 23442305 PMCID: $\underline{3607519}$ 
12. Anderson BO, Yip CH, and Smith RA, et al (2008) Guideline implementation for breast healthcare in low-income and middleincome countries: overview of the Breast Health Global Initiative Global Summit 2007 Cancer 113(8) 2221-2243 https://doi. org/10.1002/cncr.23844 PMID: 18816619

13. Goss PE, Lee BL, and Badovinac-Crnjevic T, et al (2013) Planning cancer control in Latin America and the Caribbean Lancet Oncol 2013 14(5) 391-436 https://doi.org/10.1016/S1470-2045(13)70048-2 PMID: 23628188

14. Lozano-Ascencio R, Gómez-Dantés H, and Lewis S, et al (2009) Breast cancer trends in Latin America and the Caribbean Salud Publica Mex 51(2) s147-s156 https://doi.org/10.1590/S0036-36342009000800004

15. MTS P (2006) Situación epidemiológica del cáncer de mama en Chile 1994-2003 Rev Med ClinCondes 17 142-148

16. Freitas R Jr, Freitas NM, and Curado MP, et al (2010) Incidence trend for breast cancer among young women in Goiania, Brazil Sao Paulo Med J 128(2) 81-84 https://doi.org/10.1590/S1516-31802010000200007 PMID: 20676574

17. Laura Itriago G, Nicolas Silva I, and Giovanna Cortes F (2013) Cáncer en chile y el mundo: unamirada epidemiológica, presente y futuro Rev Med Clin Condes 24(4) 531-552

18. Carioli G, La Vecchia C, and Bertuccio P, et al (2017) Cancer mortality predictions for 2017 in Latin America Ann Oncol 28(9) 2286-2297 https://doi.org/10.1093/annonc/mdx301 PMID: 28911064

19. World Health Organization (WHO) (2008) The global burden of disease: 2004 summary tables. October 2008 update (Geneva, Switzerland: World Health Organization)

20. Chile MDSD (2012) Primer informe de registro poblacional de cancer en chile. Quinquenio 2003-2007. Unidad de vigilancia de enfermedades no transmisibles y estudios departamento de epidemiología división planificación sanitaria subsecretaría de salud pública (Ministerio de salud de Chile) p 178

21. Perou CM, Sørlie T, and Eisen MB, et al (2000) Molecular portraits of human breast tumours Nature 406(6797) 747-752 https:// doi.org/10.1038/35021093 PMID: 10963602

22. Curigliano G, Burstein HJ, and Winer EP, et al (2017) De-escalating and escalating treatments for early-stage breast cancer: the St. Gallen International Expert Consensus Conference on the Primary Therapy of Early Breast Cancer 2017 Ann Oncol 28(8) 1700-1712 https://doi.org/10.1093/annonc/mdx308 PMID: 28838210 PMCID: 6246241

23. Cheang MC, Martin M, and Nielsen TO, et al (2015) Defining breast cancer intrinsic subtypes by quantitative receptor expression Oncology 20 474-482 https://doi.org/10.1634/theoncologist.2014-0372

24. Prat A, Adamo B, and Cheang MC, et al (2013) Molecular characterization of basal-like and non-basal-like triple-negative breast cancer Oncology 18 123-133 https://doi.org/10.1634/theoncologist.2012-0397

25. Lehmann BD, Jovanović $B$, and Chen $X$, et al (2016) Refinement of triple-negative breast cancer molecular subtypes: implications for neoadjuvant chemotherapy selection PLoS One 11(6) e0157368 https://doi.org/10.1371/journal.pone.0157368 PMID: 27310713 PMCID: 4911051

26. Boyle P (2012) Triple-negative breast cancer: epidemiological considerations and recommendations Ann Oncol 23(6) 8-13 https://doi.org/10.1093/annonc/mds187

27. Foulkes WD, Smith IE, and Reis-Filho JS (2010) Triple-negative breast cancer N Engl J Med 363 1938-1948 https://doi.org/10.1056/ NEJMra1001389 PMID: 21067385

28. Dent R, Trudeau M, and Pritchard KI, et al (2007) Triple-negative breast cancer: clinical features and patterns of recurrence Clin Cancer Res 13(15) 4429-4434 https://doi.org/10.1158/1078-0432.CCR-06-3045 PMID: 17671126

29. Carey LA, Perou CM, and Livasy CA, et al (2006) Race, breast cancer subtypes, and survival in the carolina breast cancer study JAMA 295(21) 2492 https://doi.org/10.1001/jama.295.21.2492 PMID: 16757721

30. Bauer KR, Brown M, and Cress RD, et al (2007) Descriptive analysis of estrogen receptor (ER)-negative, progesterone receptor (PR)-negative, and HER2-negative invasive breast cancer, the so-called triple-negative phenotype: a population-based study from the california cancer registry Cancer 109(9) 1721-1728 https://doi.org/10.1002/cncr.22618 PMID: 17387718 
31. Harris LN, Broadwater G, and Lin NU, et al (2006) Molecular subtypes of breast cancer in relation to paclitaxel response and outcomes in women with metastatic disease: results from CALGB 9342 Breast Cancer Res 8(6) R66 https://doi.org/10.1186/ bcr1622 PMID: 17129383 PMCID: 1797029

32. Howlader N, Altekruse SF, and $\mathrm{Li} \mathrm{Cl}$, et al (2014) US incidence of breast cancer subtypes defined by joint hormone receptor and HER2 status J Natl Cancer Inst 106(5) https://doi.org/10.1093/jnci/dju055 PMID: 24777111 PMCID: 4580552

33. Villarreal-Garza C, Aguila C, and Magallanes-Hoyos MC, et al (2013) Breast cancer in young women in Latin America: an unmet, growing burden Oncologist 18(12) 1298-1306 https://doi.org/10.1634/theoncologist.2013-0321 PMID: 24277771 PMCID: 3868424

34. Acevedo F, Camus M, and Sanchez C (2015) Breast cancer at extreme ages-a comparative analysis in Chile Asian Pac J Cancer Prev 16(4) 1455-1461 https://doi.org/10.7314/APJCP.2015.16.4.1455 PMID: 25743815

35. Bianchini G, Balko JM, and Mayer IA, et al (2016) Triple-negative breast cancer: challenges and opportunities of a heterogeneous disease Nat Rev Clin Oncol 13(11) 674-690 https://doi.org/10.1038/nrclinonc.2016.66 PMID: 27184417 PMCID: $\underline{5461122}$

36. Liedtke C, Mazouni C, and Hess KR, et al (2008) Response to neoadjuvant therapy and long-term survival in patients with triple-negative breast cancer J Clin Oncol 26 1275-1281 https://doi.org/10.1200/JC0.2007.14.4147 PMID: 18250347

37. Guarneri V, Broglio K, and Kau SW, et al (2006) Prognostic value of pathologic complete response after primary chemotherapy in relation to hormone receptor status and other factors J Clin Oncol 24 1037-1044 https://doi.org/10.1200/JC0.2005.02.6914 PMID: 16505422

38. Cortazar P, Zhang L, and Untch M, et al (2014) Pathological complete response and long-term clinical benefit in breast cancer: the CTNeoBC pooled analysis Lancet 384 164-172 https://doi.org/10.1016/S0140-6736(13)62422-8 PMID: 24529560

39. von Minckwitz G, Schneeweiss A, and Loibl S, et al (2014) Neoadjuvant carboplatin in patients with triple-negative and HER2positive early breast cancer (GeparSixto; GBG 66): a randomised phase 2 trial Lancet Oncol 15(7) 747-756 [doi: 10.1016/S14702045(14)70160-3] https://doi.org/10.1016/S1470-2045(14)70160-3 PMID: 24794243

40. Hahnen E, Lederer B, and Hauke J, et al (2017) Germline mutation status, pathological complete response, and disease-free survival in triple-negative breast cancer: secondary analysis of the geparSixto randomized clinical trial JAMA Oncol 3(10) 1378-1385 [doi: 10.1001/jamaoncol.2017.1007] https://doi.org/10.1001/jamaoncol.2017.1007 PMID: 28715532 PMCID: $\underline{5710508}$

41. Denkert C, Liedtke C, and Tutt A, et al (2017) Molecular alterations in triple-negative breast cancer-the road to new treatment strategies Lancet 389(10087) 2430-2442 https://doi.org/10.1016/S0140-6736(16)32454-0

42. Robson M, Im S, and Senkus E, et al (2017) Olaparib for metastatic breast cancer in patients with a germline BRCA mutation NEJM 3776 https://doi.org/10.1056/NEJMoa1706450

43. Sanabria M, Muñoz G, and Vargas C (2009) Análisis de las mutaciones más frecuentes del gen BRCA1 en mujeres con cáncer de mama en Bucaramanga, Colombia Revista Biomédica 29(1)

44. Arias-Blanco F, Ospino-Durán J, and Restrepo-Fernández E, et al (2015) Prevalencia de mutación y de variantes de secuencia para los genes BRCA1 y BRCA2 en una muestra de mujeres colombianas con sospecha de síndrome de cáncer de mama hereditario: serie de casos Revista Colombiana de Obstetricia y Ginecología 66 287. [http://www.bibliotecaminsal.cl/wp/wp-content/ uploads/2016/04/0712015-GPC-CaMama-Final-Ly-P-Publicaci\%C3\%B3n.pdf] https://doi.org/10.18597/rcog.294

45. Carey LA, Dees EC, and Sawyer L, et al (2007) The triple negative paradox: primary tumor chemosensitivity of breast cancer subtypes Clin Cancer Res 13 2329-2334 https://doi.org/10.1158/1078-0432.CCR-06-1109 PMID: 17438091

46. Rolfo C, Caglevic C, and Bretel D, et al (2016) Cancer clinical research in Latin America: current situation and opportunities. Expert opinion from the first ESMO workshop on clinical trials, Lima, 2015 ESMO Open 1(4) e000055 https://doi.org/10.1136/ esmoopen-2016-000055 PMID: $\underline{27843620}$ PMCID: $\underline{5070258}$ 